\title{
NEW EVIDENCE ON EXPIRATION-DAY EFFECTS USING REALIZED VOLATILITY: AN INTRADAY ANALYSIS FOR THE SPANISH STOCK EXCHANGE*
}

\author{
Manuel Illueca and Juan Ángel Lafuente ${ }^{* *}$
}

WP-EC 2006-05

Correspondencia: Universitat Jaume I, Departamento de Finanzas y Contabilidad, Campus del Riu Sec, 12071 Castellón. E-mail: lafuen@cofin.uji.es

Editor: Instituto Valenciano de Investigaciones Económicas, S.A.

Primera Edición Febrero 2006

Depósito Legal: V-1115-2006

Los documentos de trabajo del IVIE ofrecen un avance de los resultados de las investigaciones económicas en curso, con objeto de generar un proceso de discusión previo a su remisión a las revistas científicas

\footnotetext{
* J.A. Lafuente acknowledges financial support from the Spanish Ministry of Education through grant BEC200303965.

** M. Illueca: Universitat Jaume I; Instituto Valenciano de Investigaciones Económicas. J.A. Lafuente: Universitat Jaume I. Correspondence to: Department of Finance and Accounting, Universitat Jaume I, Campus del Riu Sec, 12071 Castellón (Spain). E-mail: lafuen@cofin.uji.es
} 


\title{
NEW EVIDENCE ON EXPIRATION-DAY EFFECTS USING REALIZED VOLATILITY: AN INTRADAY ANALYSIS FOR THE SPANISH STOCK EXCHANGE
}

\author{
M. Illueca y J. A. Lafuente
}

\begin{abstract}
In this paper we provide additional evidence on expiration effects in the Ibex 35 stock index futures market using realized volatility as proposed in Andersen et al. (2003, Econometrica 71, 529-626). Our findings reveal not only a significant increase in spot trading activity, but also the existence of a significant jump in spot volatility at index futures expiration. Moreover, we analyze the importance of the data frequency considered, revealing that the use of GARCH methodology from daily data does not have the ability to statistically assess such expiration-day effect. Additional empirical evidence is provided for the S\&P 500 stock index futures market. Neither unconditional nor conditional realized volatility has a significant increase at expiration for the US market, suggesting that this effect is specific for the Spanish market, at least for the period analyzed.
\end{abstract}

Keywords: Futures Markets, Realized volatility, spot market destabilization

JEL Classification: G14, G19, G 12

\section{RESUMEN}

Este artículo proporciona nueva evidencia empírica sobre el efecto del vencimiento de los contratos de futuros sobre el índice IBEX 35, utilizando la medida de volatilidad realizada propuesta en Andersen et al. (2003, Econometrica 71, 529-626). Nuestros resultados ponen de manifiesto que al vencimiento de los contratos de futuros se produce no sólo un incremento en el volumen negociado en el mercado de contado, sino también un incremento significativo de la volatilidad del activo subyacente. Además, el trabajo pone de manifiesto la importancia de contar con información intradía para llevar a cabo el análisis empírico. De hecho, el uso de la metodología GARCH a partir de datos diarios no permite apreciar las anomalías que se producen en el mercado de contado cuando vencen los contratos de futuros. También se proporciona evidencia empírica relativa al mercado de futuros sobre el índice S\&P 500. En este caso, ni la volatilidad condicionada ni la volatilidad no condicionada aumentan significativamente en los días de vencimiento de los contratos de futuros, sugiriendo que la evidencia reportada en este trabajo constituye una característica específica del mercado español, al menos durante el periodo analizado.

Palabras clave: Mercados de futuros, Volatilidad realizada, Desestabilización del mercado de contado 


\section{INTRODUCTION}

Previous research on expiration-day effects has generally found that spot trading volume is abnormally high at expiration. However, in spite of the well-documented positive correlation between trading volume and stock price volatility, no higher volatility is systematically reported. The main objective of this paper is to provide additional insights into expiration effects on volume and volatility for the Ibex 35 and S\&P 500 stock index markets.

Relative to previous literature, the contribution of the paper lies in the use of realized volatility as proposed in Andersen et al. (2003, Econometrica 71, 529-626). As far as we are aware, this volatility measure has not yet been used to test expiration-day effects on volatility. Moreover, in contrast to previous studies on the Spanish market (Aragó and Fernández, 2002 and Corredor et al., 2001), we use intraday high frequency data to specifically investigate volatility effects around the trading interval in which the settlement price of the futures contract is computed. Our findings for the Spanish market can be summarized as follows: a) a significant increase of spot trading activity is detected at expiration, b) according to the Mixture of Distribution Hypothesis, a significant jump in conditional realized volatility is also observed at maturity, especially during the trading period where the average settlement price is calculated, and c) of particular interest no volatility effects arise when daily spot returns are used. Specifically, both univariate GARCH methodology and squared close-to-close returns lead to the rejection of the null hypothesis of higher volatility at expirations. However, empirical findings for the S\&P 500 stock index market do not support a significant increase of volatility at expirations, suggesting a specific behavior of Spanish spot market at futures maturity.

The rest of the paper is organized as follows: After reviewing the existing literature in section 2, section 3 describes the data and the construction of the trading activity variable. Section 4 presents empirical evidence on volume and volatility effects in the Spanish market. Section 5 discusses the importance of the data frequency for the Spanish market and provides empirical evidence of expiration day effects on volatility for the Standard and Poor's 500 stock index. Finally, Section 6 gives concluding remarks.

\section{LITERATURE REVIEW}

There is extensive empirical evidence on the expiration-day effects of US derivatives markets, where the triple witching hour has encouraged specific studies (see Stoll and 
Whaley, 1987, 1990, 1991, Feinstein and Goetzmann 1988, Herbst and Maberly, 1990, Hancock, 1993 and Chen and Williams, 1994). Empirical results generally report abnormally high trading volume and lower

average returns on expiration days. However, the downward pressure on the underlying stock market does not tend to reverse at the next opening, suggesting that expiration should not be associated with this price pattern. Similar findings are detected when expiration-day effects are analyzed in other countries (see Pope and Yadav, 1992, Karolyi, 1996, Stoll and Whaley, 1997, Corredor et al., 2001 and Chow et al., 2003, among others).

However, the effect on price volatility is far from conclusive. For instance, Stoll and Whaley (1990) and Hancock (1993) found that, even though change in the settlement price of the S\&P 500 mitigates the triple witching hour effect, the Friday opening on the expiration day is associated with higher volatility in the spot market. Stoll and Whaley (1997) also found evidence of some increased volatility in individual stock returns in the Australian Stock Exchange. Chow et. al. (2003) provide evidence of abnormal volatility in the Hang Seng Index relative to one and five trading days before the expiration of their futures and options derivative contracts. However, other studies have found no significant effects on volatility. Pope and Yadav (1992) analyzed all options expirations from October 1982 to September 1987 in the London Stock Exchange. These authors could not reject the null hypothesis that the variance of stock returns in the event period (the time interval spanning from 4 days before and 5 days after the expiration day) is equal to the variance of stock return in the control period. Karolyi (1996) tested whether the intraday return volatility of Japanese stocks in the final trading hours of expiration days and the first hours following expirations is equal to that of non-expiration days. He found that differences in volatility are negligible. Finally, Corredor et al. (2001) provided empirical evidence suggesting that the expiration of the Ibex 35 index derivatives has no significant effect on the conditional variance of the Ibex 35 spot index.

A great number of studies have thoroughly documented the relationship between intraday price changes and trading activity in financial markets (Karpoff, 1987), revealing a positive and contemporaneous correlation between price volatility and trading volume (see Lamoureux and Lastrapes, 1990, Andersen, 1996 and Rahman et al., 2002, among others). Several theoretical models have attempted to explain this empirical finding (Clark, 1973, Epps and Epps, 1976, Copeland, 1976, Admati and Pfleiderer, 1988 and Suominen, 2001). The central idea behind these theoretical contributions is that volume and returns jointly depend on an underlying latent variable that represents the rate of information flow to the market (the Mixture of Distribution Hypothesis). The correlation arises because volume and volatility are increasing functions of this latent variable. 
In sum, while there is overwhelming empirical evidence to support the existence of a positive correlation between volume and volatility in equity markets, no higher spot price fluctuations are systematically associated with the abnormal spot trading volume observed at expirations. This paper revises the nature of this relationship at futures expiration for the Ibex 35 and Standard and Poor's 500 stock index market.

\section{DATA}

Intraday data on the Ibex 35 spot market were provided by MEFF RV \{Mercado Español de Futuros, Renta Variable) for the period January 172000 through December 20 $2002^{1}$. We selected 15-minute prices and then generated the percent return series for Ibex 35 by taking the first difference of the natural logarithm. This procedure finally gave 35 return observations for each trading day, including the overnight (close-to-open) return. Overall, we obtained 25,445 return observations. As to the S\&P 500 index market, intraday data were supplied by “Tick Data Inc.", and a similar data set was produced.

\subsection{Daily realized volatility}

Following Andersen et al. (2003), the daily volatility of the spot index is measured by the sum of squared 15-minute intraday returns and the squared close-to-open return:

$$
R V_{t}=\left(r_{t}^{\text {overnight }}\right)^{2}+\sum_{j=1}^{34}\left(r_{t, j}^{\text {int rday }}\right)^{2}
$$

where $r_{t}^{\text {overnight }}$ denotes the return from the close on day $t-1$ to the open on day $t$, and $r_{t, j}^{\text {intraday }}$ refers to the intraday 15 -minute return on day $t$ for intraday interval $j$. Finally we get 727 daily observations of spot realized volatility.

The settlement price of the Ibex 35 futures contract is computed at expiration as the arithmetic average index value between 16:15 and 16:45 hours, taking a value per minute. Given the objective of the paper, two intraday realized volatilities are considered: a) from 16:00 to 17:30 hours (around the settlement) and b) from close on day $t-1$ to 16:00 hours on day $t$ (out of the settlement).

\footnotetext{
${ }^{1}$ From January 172000 the new intraday trading period covers 9:00 to 17:30.
} 


\subsection{Constructing daily volume variables}

According to Illueca and Lafuente (2003) and Fung and Patterson (1999), daily volume is detrended as follows:

$$
V_{t}=\frac{T V_{t}}{\frac{1}{N} \sum_{k=-\left(\frac{N-1}{2}\right)}^{\frac{N-1}{2}} T V_{t+k}}
$$

where $T V_{t}$ is the trading volume corresponding to day $t$, and $N$ is the number of observations used to capture the trend of the series. The number of observations considered in the moving average $(N=31)$ was chosen to preserve the relative abnormal spot volume observed at expiration date from raw volume data. This procedure gives a detrended time series that incorporates the short-run movements in trading volume within the life cycle of the futures contract. Overall, we have 697 daily observations of spot trading volume. The empirical values of the Augmented Dickey Fuller test, not reported in the paper ${ }^{2}$, corroborate that the detrended volume series are stationary.

\section{EXPIRATION EFFECTS IN THE SPANISH MARKET}

\subsection{Effects on trading activity}

To study whether the trading volume in the stock market departs at expiration from "normal" trading activity, Figure I depicts the intraday average trading volume corresponding to the expiration dates and the alternative control subsamples. In accordance with previous literature, higher trading volume arises at maturity. The average increase in trading volume is close to $24 \%$. As expected, the highest difference is observed in the final interval, when the settlement price of the futures contract is established and the unwinding of arbitrage positions takes place. Within the last interval, the average trading volume is around $33 \%$ higher than that of the control periods.

\footnotetext{
${ }^{2}$ Available from the authors upon request.
} 
Figure I

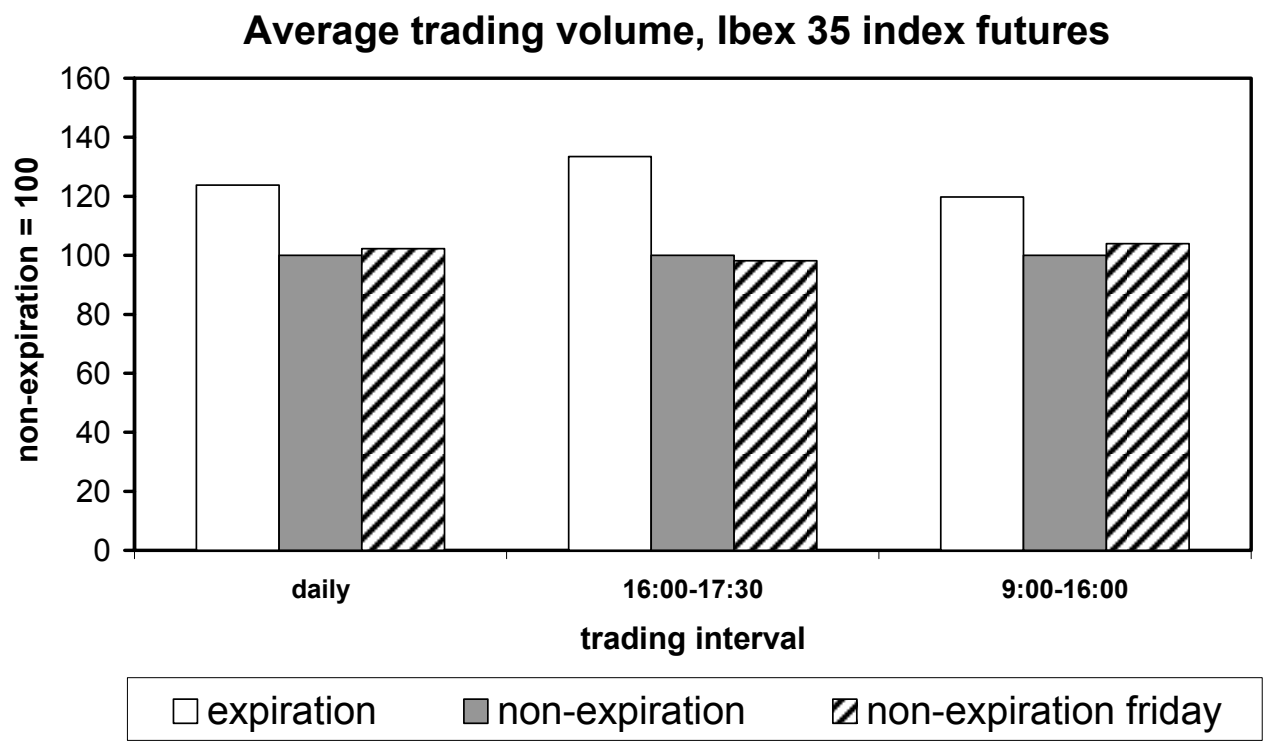

To statistically test whether the average increase in trading volume is significantly higher at expiration, we ran the following regression for daily data and intraday data covering both 9:00 to 16.00 and $16: 00$ to $17: 30$ hours:

$$
V_{t}=\alpha+\beta_{1} D_{1}+\beta_{2} D_{2}+\sum_{k=1}^{p} \gamma_{k} V_{t-k}+\varepsilon_{t}
$$

where $V_{t}$ is the detrended volume at time $t, D_{1}$ is a dummy variable that takes the value unity if $t$ is an expiration day and $D_{2}$ is a dummy variable that takes the value unity if $t$ is a Friday. This allows us to capture potential seasonal effects associated with the last trading day of the week. The lag length is determined according to the Akaike information criterion.

Table I reports the parameter estimates of $\beta_{i}, i=1,2$ for each subsample considered. Our empirical results confirm that, relative to non-expiration, spot volume is significantly higher in the event period.

\subsection{Effects on volatility}

In this section we investigate expiration-day effects on volatility. The central hypothesis to be tested here is whether trading activity prompted by the unwinding of index arbitrage positions leads to higher spot price fluctuations. To account for this hypothesis, the researcher can analyze the potential effects either on conditional or unconditional volatility, regardless of the frequency of the data used. 
Table I.

\begin{tabular}{lcc}
\hline Ibex 35 index futures & $\hat{\beta}_{1}$ & $\hat{\beta}_{2}$ \\
\hline Daily & $0.206(0.055)^{\mathrm{a}}$ & $0.018(0.024)$ \\
{$[09: 00-16: 00]$} & $0.151(0.061)^{\mathrm{b}}$ & $0.029(0.026)$ \\
{$[16: 00-17: 30]$} & $0.342(0.062)^{\mathrm{a}}$ & $-0.016(0.028)$ \\
\hline
\end{tabular}

This table shows the parameter estimates of $\beta_{1}$ and $\beta_{2}$ in the following equation:

$$
V_{t}=\alpha+\beta_{1} D_{1}+\beta_{2} D_{2}+\sum_{j=1}^{p} \gamma_{j} V_{t-j}+\varepsilon_{t}
$$

where $V_{t}$ is the detrended volume of the Ibex 35 index futures at time $t, D_{1}$ is a binary variable that takes the value unity if $t$ is an expiration day and $D_{2}$ is a binary variable that takes the value unity if $t$ is a Friday. The lag structure is determined according to the Akaike information criterion ( $p=12$ for daily and 09:00 to 16:00 trading volume and $p=13$ for 16:00 to 17:30 trading volume). White heteroskedasticity-consistent standard errors are given in parentheses. ${ }^{a, b}$ denote statistical significance at $1 \%$ and $5 \%$ levels, respectively.

\subsection{Effects on unconditional realized volatility}

Previous empirical work in the literature has mainly focused on the effects on unconditional volatility. For example, Chow et al., 2003, Stoll and Whaley, 1997, Karolyi, 1996 compare the standard deviation of intraday returns at expirations with that corresponding to control subsamples. In accordance with this approach, we first test whether unconditional realized volatility significantly augments at expirations. To do this, the following regression was run using daily realized volatility as well as realized volatility corresponding to the partition previously mentioned (9:00 to $16: 00$ and 16.00 to 17:30 hours)

$$
R V_{t}=\alpha+\beta_{1} D_{1}+\beta_{2} D_{2}+\varepsilon_{t}
$$

Table II summarizes the empirical results. Firstly, significant seasonal effects are detected, showing that realized volatility is generally lower on Fridays. This pattern arises not only for daily but also for intraday volatility. Secondly, the null hypothesis that spot return volatility at expiration is equal to that of non-expiration days cannot be rejected at conventional levels. Only for the trading interval around the settlement can the null be rejected at $10 \%$ significance level. However, it should be highlighted that the empirical value of the test lies close to the upper limit of the critical region (indeed, the $p$-value is 0.098 ). 
Table II

\begin{tabular}{lcc}
\hline Realized volatility of the Ibex 35 & $\hat{\beta}_{1}$ & $\hat{\beta}_{2}$ \\
& $1.17 \times 10^{-4}\left(7.76 \times 10^{-5}\right)$ & $-6.01 \times 10^{-5}\left(2.24 \times 10^{-5}\right)^{\mathrm{a}}$ \\
\hline Daily & $6.82 \times 10^{-5}\left(5.17 \times 10^{-5}\right)$ & $-4.88 \times 10^{-5}\left(2.01 \times 10^{-5}\right)^{\mathrm{b}}$ \\
{$[09: 00-16: 00]$} & $4.89 \times 10^{-5}\left(2.95 \times 10^{-5}\right)^{\mathrm{c}}$ & $-1.14 \times 10^{-5}\left(4.15 \times 10^{-6}\right)^{\mathrm{a}}$ \\
\hline$[16: 00-17: 30]$ & & \\
\hline
\end{tabular}

This table shows the parameter estimates of $\beta_{1}$ and $\beta_{2}$ in the following equation:

$$
R V_{t}=\alpha+\beta_{1} D_{1}+\beta_{2} D_{2}+\varepsilon_{t}
$$

where $R V_{t}$ is the realized volatility at time $t$ of the Ibex 35 stock index, $D_{1}$ is a binary variable that takes the value unity if $t$ is an expiration day and $D_{2}$ is a binary variable that takes the value unity if $t$ is a Friday. The Newey-West heteroskedasticity and autocorrelation consistent standard errors are given in parentheses. ${ }^{\text {a,b,c }}$ denote statistical significance at $1 \%, 5 \%$ and $10 \%$ levels, respectively.

In sum, at this stage, our findings are similar to those reported in Stoll and Wahley (1997) and Karolyi (1996) for the Australian All Ordinaries Index and the Nikkei stock average, respectively. However, the use of unconditional realized volatility could lead to the misunderstanding of conclusions when explanatory variables of volatility are omitted. For example, Andersen et al. (2001) show that realized volatility is characterized by significant temporal dependence. Moreover, extensive finance literature reports a positive correlation between trading volume and return volatility (Karpoff, 1987). Hence, in the next subsection we move onto the effects on conditional realized volatility.

\subsection{Effects on conditional realized volatility}

In addition to lagged values of realized volatility, considered to account for serial dependence, there might be other relevant variables that could explain current realized volatility. In a recent study, Luu and Martens (2003) provide empirical evidence supporting the Mixture of Distribution Hypothesis (MDH, hereafter) when realized volatility is used. Under MDH, originally introduced by Tauchen and Pitts (1983), price changes per unit of calendar time are the sum of the price changes occurring during that period. If it is assumed that a) prices evolve when new information arrives in the market and b) the number of information arrivals is random, a positive correlation is expected between volume and absolute returns, as volume is positively correlated with the number of information arrivals in the market. Moreover, under the assumption that the information arrival rate is autocorrelated (Andersen, 1996), a positive correlation between current volatility and lagged volume is expected. 
Therefore, to test the existence of expiration-day effects on conditional realized volatility, the following econometric specification is used:

$$
R V_{t}=\alpha+\beta_{1} D_{1}+\beta_{2} D_{2}+\sum_{j=1}^{p} \gamma_{j} V_{t-j}+\sum_{j=1}^{p} \delta_{j} R V_{t-j}+\varepsilon_{t}
$$

where $V_{t}$ is the detrended volume at time $\mathrm{t}, R V_{t}$ is the realized volatility at time t, $D_{1}$ is a dummy variable that takes the value unity if $\mathrm{t}$ is an expiration day and $D_{2}$ is a dummy variable that switches on Fridays to capture potential seasonal effects. The lag length is determined according to the Akaike information criterion.

Table III provides the point estimates of parameters in equation (3). In accordance with previous findings corresponding to unconditional realized volatility, the parameter $\beta_{2}$ is negative and statistically different from zero at least at 5\% significance level. Interestingly enough, when daily realized volatility is considered, the point estimate of parameter $\beta_{1}$ is positive and significant at $1 \%$ level. As to intraday realized volatility, similar qualitative findings are found. However, it should be highlighted that $\beta_{1}$ is significant only at $10 \%$ level for the interval out of the settlement, whereas around the settlement the parameters become significant at $1 \%$ level. In sum, in contrast to previous findings based on unconditional realized volatility, empirical evidence from conditional volatility suggests the existence of a significant jump in volatility at expirations, specially at the end of the trading session.

\section{Table III}

\begin{tabular}{ccc}
\hline Realized volatility of the Ibex 35 & $\hat{\beta}_{1}$ & $\hat{\beta}_{2}$ \\
\hline Daily & $1.19 \times 10^{-4}\left(4.54 \times 10^{-5}\right)^{\mathrm{a}}$ & $-9.50 \times 10^{-5}\left(4.39 \times 10^{-5}\right)^{\mathrm{b}}$ \\
{$[09: 00-16: 00]$} & $7.30 \times 10^{-5}\left(3.91 \times 10^{-5}\right)^{\mathrm{c}}$ & $-7.75 \times 10^{-5}\left(4.07 \times 10^{-5}\right)^{\mathrm{c}}$ \\
{$[16: 00-17: 30]$} & $3.80 \times 10^{-5}\left(1.40 \times 10^{-5}\right)^{\mathrm{a}}$ & $-1.07 \times 10^{-5}\left(4.97 \times 10^{-6}\right)^{\mathrm{b}}$ \\
\hline
\end{tabular}

This table shows the parameter estimates of $\beta_{1}$ and $\beta_{2}$ in the following equation:

$$
R V_{t}=\alpha+\beta_{1} D_{1}+\beta_{2} D_{2}+\sum_{j=1}^{p} \gamma_{j} V_{t-j}+\sum_{j=1}^{p} \delta_{j} R V_{t-j}+\varepsilon_{t}
$$

where $V_{t}$ is the detrended volume at time $t, R V_{t}$ is the realized volatility at time $t$ of the Ibex 35 stock index, $D_{1}$ is a binary variable that takes the value unity if $t$ is an expiration day and $D_{2}$ is a binary variable that takes the value unity if $t$ is a Friday. The lag structure is determined according to the Akaike information criterion $(p=12)$. White heteroskedasticity-consistent standard errors are given in parentheses. ${ }^{\text {a,b,c }}$ denote statistical significance at $1 \%, 5 \%$ and $10 \%$ levels, respectively. 


\section{FURTHER ANALYSIS}

\subsection{Sample size and the Lindley Paradox}

Given the relatively large sample size used in this paper (697 observations), one additional issue that arises in the context of our empirical analysis is Lindley's (1957) paradox. When using large sample sizes, there is a tendency to reject the null hypothesis at conventional significance levels even when posterior odds favor the null (see Zellner and Siow, 1980 for a discussion of this question in the context of regression analysis). To overcome this issue, Connolly (1989) provides formulas for calculating sample size-adjusted critical values for $t$-statistics ${ }^{3}$ :

$$
t^{*}=\left[(T-k)\left(T^{1 / T}-1\right)\right]^{\frac{1}{2}}
$$

where $T$ is the sample size and $K$ is the number of parameters estimated. The above expression corresponds to prior odds being 1 to 1 . According to this Bayesian inference procedure, a parameter is significantly different from zero when its standard $t$ value is greater than $t^{*}$. Concerning regressions involved in Table III, the adjusted sample size critical value is: $t^{*}=\left[(697-27)\left(697^{1 / 697}-1\right)\right]^{\frac{1}{2}}=2,51$. According to Table III, $\beta_{1}$ remains statistically different from zero for the regression of realized volatility computed either from 9:00 to 17:30 hours or from 16:00 to 17:30 hours. These findings imply that the nature of the empirical evidence previously reported remains qualitatively unchanged, that is, we detect a significant expiration day effect on volatility, specially around the trading interval in which the settlement price of the futures contract is computed.

\subsection{The importance of volatility measure}

Some previous studies on expiration-day effects do not use intraday data. In these cases, the volatility measure relies on closing spot prices. For example, Pope and Yadav (1992) estimate unconditional spot volatility on individual equities traded on the London Stock Exchange as the squared close-to-close return. For the Spanish market, Corredor et al. (2001) use the univariate GARCH methodology to estimate conditional volatility of Ibex 35

\footnotetext{
${ }^{3}$ As pointed out by Szakmary and Kiefer (2004), an obvious typo appears in the reported equation for critical $t$ values in Connolly (1989, p. 140).
} 
spot returns. In this subsection we discuss the importance of using a volatility measure based on high frequency data to test the existence of expiration-day effects on volatility.

Let us assume that only closing prices are available. In such circumstances, unconditional spot volatility can be estimated by computing the squared close-to-close Ibex35 index return (Pope and Yadav, 1992). Then, to test the null hypothesis of higher volatility at expirations, the following regression is used:

$$
r_{t}^{2}=\alpha+\beta_{1} D_{1}+\beta_{2} D_{2}+\varepsilon_{t}
$$

where $r_{t}=\ln \left(\begin{array}{c}P_{t}^{\text {close }} \\ \end{array} P_{t-1}^{\text {close }}\right)$ and $\mathrm{P}$ refers to the Ibex 35 spot index. Empirical results are reported in Panel A of Table IV. Despite the fact that the daily squared returns are very noisy volatility proxies, $\beta_{1}$ is not significant at conventional levels, which leads to similar conclusions to those obtained from daily unconditional realized volatility.

We now turn towards the effects on conditional volatility. To analyze the robustness of the empirical results previously reported in Table IV (relative to conditional realized volatility), two alternative approaches are used. We first estimate equation (4) adding lagged values of squared close-to-close returns and volume. Secondly, in accordance with Corredor et al. (2001), we estimate an AR(1) process with heteroskedastic errors for Ibex 35 index returns ${ }^{4}$. In particular, the specification of the variance equation is a GJR-GARCH $(1,1)$ which includes $D_{1}$ and $D_{2}$ dummy variables, that is:

$$
\begin{gathered}
r_{t}=\alpha+\beta r_{t-1}+\varepsilon_{t} \quad \varepsilon_{t} / \Omega_{t-1} \sim N\left(0, \sigma_{t}^{2}\right), \\
\sigma_{t}^{2}=\gamma_{0}+\beta_{1} D_{1}+\beta_{2} D_{2}+\sum_{j=1}^{p} \gamma_{i} \sigma_{t-j}^{2}+\sum_{j=1}^{q} \phi_{j} \varepsilon_{t-j}^{2}+\delta \varepsilon_{t-1}^{2} d_{t-1},
\end{gathered}
$$

where ${ }^{d_{t}}$ is a binary variable that takes the value unity when $\varepsilon_{t}<0$.

\footnotetext{
${ }^{4}$ The Engle Lagrange-multiplier test, not reported in the paper, reveals that close-to-close Ibex 35 returns have an ARCH structure within the sample period analyzed.
} 
Table IV

\begin{tabular}{|c|c|c|}
\hline & $\hat{\beta}_{1}$ & $\hat{\beta}_{2}$ \\
\hline & \multicolumn{2}{|c|}{ Panel A } \\
\hline \multirow{2}{*}{ Squared close-to-close returns } & $1.04 \times 10^{-4}\left(1.03 \times 10^{-4}\right)$ & $-2.62 \times 10^{-5}\left(5.26 \times 10^{-5}\right)$ \\
\hline & \multicolumn{2}{|c|}{ Panel $B^{(*)}$} \\
\hline \multirow[t]{2}{*}{ Squared close-to-close returns } & $1.05 \times 10^{-4}\left(1.01 \times 10^{-4}\right)$ & $-4.30 \times 10^{-5}\left(6.19 \times 10^{-5}\right)$ \\
\hline & \multicolumn{2}{|c|}{ Panel $C^{(* *)}$} \\
\hline GJR-GARCH & $-6.65 \times 10^{-5}\left(3.54 \times 10^{-5}\right)^{c}$ & $1.32 \times 10^{-5}\left(2.96 \times 10^{-5}\right)^{\mathrm{a}}$ \\
\hline
\end{tabular}

This table shows the parameter estimates of $\beta_{1}$ and $\beta_{2}$ in the following equations:

$$
\begin{array}{ll}
S R_{t}=\alpha+\beta_{1} D_{1}+\beta_{2} D_{2}+\varepsilon_{t} & \text { Panel } A \\
S R_{t}=\alpha+\beta_{1} D_{1}+\beta_{2} D_{2}+\sum_{j=1}^{p} \gamma_{j} V_{t-j}+\sum_{j=1}^{p} \delta_{j} S R_{t-j}+\varepsilon_{t} & \text { Panel } B \\
r_{t}=\alpha+\beta r_{t-1}+\varepsilon_{t} \quad \varepsilon_{t} / \Omega_{t-1} \sim N\left(0, \sigma_{t}^{2}\right) & \\
\sigma_{t}^{2}=\gamma_{0}+\beta_{1} D_{1}+\beta_{2} D_{2}+\sum_{j=1}^{p} \gamma_{i} \sigma_{t-j}^{2}+\sum_{j=1}^{q} \phi_{j} \varepsilon_{t-j}^{2}+\delta \varepsilon_{t-1}^{2} d_{t-1} & \text { Panel } C
\end{array}
$$

where $S R_{t}$ is the squared close-to-close returns at time $t$ of the Ibex 35 stock index, $D_{1}$ is a binary variable that takes the value unity if $t$ is an expiration day and $D_{2}$ is a binary variable that takes the value unity if $t$ is a Friday. Robust errors are reported in parentheses (HAC Newey-West errors in Panel A, White heteroskedasticity-consistent standard errors in Panel B and Bollerslev-Wooldridge standard errors in Panel C). ${ }^{\mathrm{a}, \mathrm{b}, \mathrm{c}}$ denote statistical significance at $1 \%, 5 \%$ and $10 \%$ levels, respectively.

${ }^{(*)}$ The lag structure is determined according to the Akaike information criterion $(p=12)$.

${ }^{(*)}$ The Ljung-Box portmanteau test from residuals and squared residuals shows no additional structure. The empirical values (and $p$-values) with 24 lags were $32.41(0.12)$ and $27.98(0.26)$, respectively. Moreover, the Bera-Jarque test reveals no significant departures from Normality in the distribution of residuals. In particular the empirical value is 2.24 with a $p$-value of 0.32 .

Surprisingly, the point estimate of parameter $\beta_{1}$ reported in Panel B and Panel C indicates that no higher volatility takes place at expirations. Moreover, in the GARCH model, the estimated parameter $\beta_{1}$ is even negative and significantly different from zero at $10 \%$ level, suggesting that conditional volatility shrinks at expirations.

In sum, relative to unconditional volatility, no significant expiration-day effects arise, regardless of the volatility measure used (squared close-to-close returns or realized volatility). However, as to conditional volatility, the frequency of the data set used becomes a crucial issue. Indeed, daily realized volatility, computed from intraday high frequency data, leads us to accept the existence of a significant increase in conditional volatility at expiration, whereas no increase is detected when volatility is estimated from a daily data basis. 


\subsection{Empirical evidence for US: volatility effects in the S\&P 500 index market}

The Spanish market has an electronic trading system and monthly maturities. To investigate whether the foregoing empirical evidence is specific to the Spanish market, this subsection provides further evidence on the S\&P 500 index futures market which allows traders to operate simultaneously through open outcry trading and an electronic trading platform (GLOBEX).

Given that S\&P index futures has four quarterly expirations, to study volume effects in the US, three alternative control subsamples are considered: a) expiration, b) one week before expiration and c) two weeks before expiration. Then, to test the effects on unconditional and conditional realized volatility the following equations are considered:

$$
\begin{gathered}
R V_{t}=\alpha+\beta_{1} D_{1}+\beta_{2} D_{2}+\beta_{3} D_{3}+\varepsilon_{t} \\
R V_{t}=\alpha+\beta_{1} D_{1}+\beta_{2} D_{2}+\beta_{3} D_{3}+\sum_{j=1}^{p} \gamma_{j} V_{t-j}+\sum_{j=1}^{p} \delta_{j} R V_{t-j}+\varepsilon_{t}
\end{gathered}
$$

where $D_{i}(i=1,2,3)$ denotes each of the dummy variables that corresponds to the abovementioned control subsamples. Tables V and VI provide the point estimates of the parameters associated with the dummy variables. In contrast to the empirical evidence reported for the Spanish market, but in accordance with most of the existing literature, no significant expiration-day effects on realized volatility are found in the US market.

\section{Table V}

\begin{tabular}{ccc}
\hline Realized volatility of the S\&P 500 & $\hat{\beta}_{1}$ & $\hat{\beta}_{2}$ \\
\hline Daily & $1.17 \times 10^{-4}\left(7.76 \times 10^{-5}\right)$ & $-6.01 \times 10^{-5}\left(2.24 \times 10^{-5}\right)^{\mathrm{a}}$ \\
{$[09: 00-16: 00]$} & $6.82 \times 10^{-5}\left(5.17 \times 10^{-5}\right)$ & $-4.88 \times 10^{-5}\left(2.01 \times 10^{-5}\right)^{\mathrm{b}}$ \\
{$[16: 00-17: 30]$} & $4.89 \times 10^{-5}\left(2.95 \times 10^{-5}\right)^{\mathrm{c}}$ & $-1.14 \times 10^{-5}\left(4.15 \times 10^{-6}\right)^{\mathrm{a}}$ \\
\hline
\end{tabular}

This table shows the parameter estimates of $\beta_{1}$ and $\beta_{2}$ in the following equation:

$$
R V_{t}=\alpha+\beta_{1} D_{1}+\beta_{2} D_{2}+\varepsilon_{t}
$$

where $R V_{t}$ is the realized volatility at time $t$ of the S\&P 500 stock index, $D_{1}$ is a binary variable that takes the value unity if $t$ is an expiration day and $D_{2}$ is a binary variable that takes the value unity if $t$ is a Friday. The Newey-West heteroskedasticity and autocorrelation consistent standard errors are given in parentheses. a,b,c denote statistical significance at $1 \%, 5 \%$ and $10 \%$ levels, respectively. 
Table VI

\begin{tabular}{lccc}
\hline $\begin{array}{l}\text { Realized volatility for the } \\
\text { S\&P 500 }\end{array}$ & $\hat{\beta}_{1}$ & $\hat{\beta}_{2}$ & $\hat{\beta}_{3}$ \\
\hline Unconditional & & & \\
& $-4.07 \times 10^{-5}$ & $7.36 \times 10^{-5}$ & $-4.61 \times 10^{-5}$ \\
& $\left(5.03 \times 10^{-5}\right)$ & $\left(5.50 \times 10^{-5}\right)$ & $\left(2.35 \times 10^{-5}\right)^{\mathrm{a}}$ \\
\hline Conditional & $-5.72 \times 10^{-5}$ & $3.80 \times 10^{-5}$ & $-1.17 \times 10^{-5}$ \\
& $\left(4.94 \times 10^{-5}\right)$ & $\left(3.50 \times 10^{-5}\right)$ & $\left(1.68 \times 10^{-5}\right)^{\mathrm{a}}$ \\
\hline
\end{tabular}

This table shows the parameter estimates of $\beta_{1}, \beta_{2}$ and $\beta_{3}$ in the following equations:

$$
\begin{array}{ll}
R V_{t}=\alpha+\beta_{1} D_{1}+\beta_{2} D_{2}+\beta_{3} D_{3}+\varepsilon_{t} & \text { Panel } A \\
R V_{t}=\alpha+\beta_{1} D_{1}+\beta_{2} D_{2}+\beta_{3} D_{3}+\sum_{j=1}^{p} \gamma_{j} V_{t-j}+\sum_{j=1}^{p} \delta_{j} R V_{t-j}+\varepsilon_{t} & \text { Panel } B
\end{array}
$$

where $R V_{t}$ is the squared close-to-close returns at time $t$ of the S\&P 500 stock index, $D_{1}$ is a binary variable that takes the value unity if $t$ is an expiration day, $D_{2}$ is a binary variable that takes the value unity if $t$ is a day within the week before expiration and $D_{3}$ is a binary variable that takes the value unity if $t$ is a day within the two weeks before expirations. Robust errors are reported in parentheses (HAC Newey-West errors in Panel A and White heteroskedasticityconsistent standard errors in Panel B). ${ }^{\mathrm{a}, \mathrm{b}, \mathrm{c}}$ denote statistical significance at $1 \%, 5 \%$ and $10 \%$ levels, respectively. The lag structure in Panel B is determined according to the Akaike information criterion $(p=9)$.

\section{SUMMARY AND CONCLUDING REMARKS}

In this paper we provide empirical evidence on expiration-day effects for the Spanish stock market throughout the period covering January 2000 to December 2002. The contribution of our paper to the literature is threefold: a) to analyze the effects on spot index fluctuations, we use realized volatility as proposed in Andersen et. al (2003), b) we investigate the effects on both conditional and unconditional realized volatility and c) a sensitivity analysis is performed to test the robustness of empirical findings to the frequency of the data used.

Consistent with previous studies in the literature, an abnormally higher spot trading volume is observed at expiration. A slight downward trend in the spot index is also detected, but the behavior of index reversals suggests that this pattern is not attributable to the maturity of the futures index derivative contract.

As to the effects on unconditional realized volatility, our findings indicate that no significant expiration-day effects arise. This empirical evidence holds even when squared close-to-close returns are used as a (very noisy) proxy of volatility. Interestingly, conditional realized volatility, which takes into account the explanatory power of lagged spot volume and 
volatility, is significantly higher at expirations, especially around the trading period designed to draw spot index values from which the settlement price of the index futures contract is computed. However, using squared close-to-close returns, the hypothesis of higher conditional spot volatility at expirations is rejected. A similar finding arises when GARCH methodology is considered to fit the behavior of daily spot returns.

In sum, our empirical findings for the Spanish case provide additional insights which allow us to better understand the inconclusive results reported in the previous literature relative to expiration-day effects on volatility. In particular, two relevant aspects should be taken into account in future research: a) the analysis of conditional versus unconditional volatility and b) the frequency of the data used to estimate volatility. Finally it should be highlighted that empirical evidence for the S\&P 500 stock index does not corroborate the results obtained for the Ibex 35 stock index, suggesting that expiration-day effects on realized stock index volatility are a specific feature of the Spanish market. 


\section{REFERENCES}

Admati A.R. and P. Pfleiderer (1988), A theory of intraday patterns: Volume and price variability, Review of Financial Studies 1, 3-40.

Andersen, T.G. (1996), Return volatility and trading volume: An information flow interpretation of stochastic volatility, Journal of Finance 51, 169-204.

Andersen, T.G., Bollerslev, T., Diebold, F.X. and H. Ebens (2001), The distribution of stock return volatility, Journal of Financial Economics 61, 43-76.

Andersen, T.G., Bollerslev, T., Diebold, F.X. and P. Labys (2003), Modeling and forecasting realized volatility, Econometrica 71, 529-626.

Aragó V. and A. Fernández (2002), Expiration and maturity effect: empirical evidence from the Spanish spot and futures stock index, Applied Economics 34, 1617-1626.

Bollerslev, T. and J.M. Wooldridge (1992), Quasi-maximum likelihood estimation and inference in dynamic models with time varying covariances, Econometric Reviews, 11, 143-172.

Chow, Y., Yung H. and H. Zhang (2003), Expiration day effects: The case of Hong Kong, Journal of Futures Markets, 23, 67-86.

Chen, C. and J. Williams (1994), Triple-witching hour, the change in expiration timing and stock market reaction, Journal of Futures Markets 14, 275-292.

Conolly, R.A. (1989), An examination of the Robustness of the Weekend Effect, Journal of Financial and Quantitative Analysis, 24, 133-169.

Copeland T.E., (1976), A model of asset trading under the assumption of sequential information arrival, Journal of Finance 31, 1149-1168.

Corredor, P, Lechón P. and R. Santamaría (2001), Option-expiration effects in small markets: The Spanish stock exchange, Journal of Futures Markets, 21, 905-928.

Epps T.W. and M.L. Epps (1976), The stochastic dependence of security price changes and transaction volumes: Implications for the mixture of distribution hypothesis, Econometrica 44, 305-321.

Hancock, G.D. (1993), Whatever happened to the triple witching hour?, Financial Analysts Journal, 45(5), 67-71.

Harris, L. (1989), S\&P 500 cash stock price volatilities, Journal of Finance, 5, 1155-1175.

Feinstein S.P. and W. Goetzmann (1988, September), The effect of the "triple witching hour" on stock market volatility, Economic Review, 2-18

Herbst, A.F. and E.D. Maberly (1990), Stock index futures, expiration day volatility, and the "special" friday opening: A note, Journal of Futures Markets 10, 323-325. 
Fung H.G. and G. A. Patterson (1999), The dynamic relationship of volatility, volume, and market depth in currency futures markets, Journal of International Financial Markets Institutions and Money, 9, 33-59.

Illueca M. and J.A. Lafuente (2003), The effect of spot and futures trading on stock index volatility: A non-parametric approach, Journal of Futures Markets 23, 841-858.

Karolyi, A.G. (1996), Stock market volatility around expiration days in Japan, Journal of Derivatives $4(2), 23-43$.

Karpoff, J.M. (1987), The relation between price changes and trading volume: A survey, Journal of Financial and Quantitative Analysis 22, 109-126.

Lamoureux C.G. and W.D. Lastrapes (1990), Heteroskedasticity in stock return data: Volume versus GARCH effects, Journal of Finance 45, 221-229.

Lindley, D.V. (1957), A statistical paradox, Biometrika 44, 187-192.

Newey, W. K. and West, K. D. (1987), A Simple Positive Definite, Heteroskedasticity and Autocorrelation Consistent Covariance Matrix, Econometrica 55, 703-705.

Pope, P.F. and P.K. Yadav (1992), The impact of option expiration on underlying stocks: The UK evidence, Journal of Business Finance and Accounting 19, 329-344.

Rahman, S., Lee C.F. and K.P. Ang (2002), Intraday return volatility process: Evidence from Nasdaq stocks, Review of Quantitative Finance and Accounting 19, 155-180.

Stoll, H.R. and R.E. Whaley (1987, March/April), Program trading and expiration day effects, Financial Analysts Journal 63, 16-28.

Stoll, H.R. and R.E. Whaley (1990), Program trading and individual stock returns: Ingredients of the triple-witching brew, Journal of Business 63, 165-192.

Stoll, H.R. and R.E. Whaley (1991, January/February), Expiration-day effects: What has changed, Financial Analysts Journal, 58-72.

Stoll, H.R. and R.E. Whaley (1997), Expiration-day effects of the All ordinaries share price index futures: Empirical evidence and alternative settlement procedures, Australian Journal of Management 22, 139-174.

Suominen, M. (2001), Trading volume and information revelation in stock markets, Journal of Financial and Quantitative Analysis 36, 545-565.

Szakmary, A.C. and D. B. Kiefer (2004), The disappearing January/turn of the year effect: Evidence from stock index futures and cash markets, Journal of Futures Markets 24, 755-784.

Tauchen, G.E. and M. Pitts (1983), The price variability-volume relationship on speculative markets, Econometrica 51, 485-505

White, H. (1980), A Heteroskedasticity-consistent covariance matrix and a direct test for heteroskedasticity, Econometrica, 48, 817-838. 
Zellner A. and A. Siow (1980), Posterior Odds Ratios for Selected Regression Hypotheses, in J.M. Bernardo, M.H. DeGroot, D.V. Lindley and A.F.M. Smith (Eds.), Bayesian Statistics: Proceedings of the First International Meeting Held in Valencia (Spain), May 28 to June 2, 1979, Valencia (Spain), University Press, 1980, 585-603. 